\title{
Improving knowledge, self-efficacy and collective efficacy regarding the Brazilian dietary guidelines in primary health care professionals: a community controlled trial
}

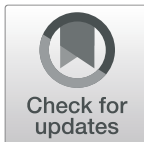

\author{
C. R. Tramontt ${ }^{1 *}$ (D) and P. C. Jaime ${ }^{2}$
}

\begin{abstract}
Background: Capacity-building of health professionals regarding to nutrition is a strategy for qualifying public health work to promote healthy diets in primary health care (PHC) services.

Objective: To evaluate the effect of an intervention based on Brazilian Dietary Guidelines (BDG) on the knowledge, self-efficacy (SE) and collective efficacy (CE) of interprofessional teams working in PHC.

Methods: It refers to a pre-post intervention study involving 24 health professionals divided into a control group (CG) and intervention (IG). The IG received a 16-h educational workshop on the BDG, guided by a validated protocol. Knowledge, SE and CE for using the BDG were assessed via a self-administered scale, ranging from 0 to 16 and 0 to 36 points, respectively; the scale was previously validated, completed before and after 2 months of the intervention. The effects of the intervention were estimated by paired t-test for intragroup comparisons over time.

Results: The mean difference in the knowledge and SE scores of the IG pre- and post-intervention was 2.0 (Cl 0.49$3.51)$ and $6.75(\mathrm{Cl} 4.05-9.45)$ points, respectively. These results means the IG participants obtained 59 and $52.8 \%$ more points in knowledge and in SE in relation to CG, with significative difference $(p=0.007$ and $p<0.00$, respectively). There was no significant variation in the CE scores in both groups.

Conclusions: Considering the results presented and due to the originality of the study in question, the educational workshop was effective in increasing the knowledge and SE of professionals working in PHC in using the Dietary Guidelines in their work routines. These findings can assist other research in developing nutrition interventions with interprofessional teams.
\end{abstract}

Keywords: Interventional study, Capacity building, Food guides, Health personnel, Primary health care

\footnotetext{
* Correspondence: claudiartramontt@gmail.com

${ }^{1}$ Nutrition in Public Health Postgraduate Program, School of Public Health, University of São Paulo, Av. Dr. Arnaldo 715, São Paulo, SP 01246-904, Brazil

Full list of author information is available at the end of the article
}

(c) The Author(s). 2020 Open Access This article is licensed under a Creative Commons Attribution 4.0 International License, which permits use, sharing, adaptation, distribution and reproduction in any medium or format, as long as you give appropriate credit to the original author(s) and the source, provide a link to the Creative Commons licence, and indicate if changes were made. The images or other third party material in this article are included in the article's Creative Commons licence, unless indicated otherwise in a credit line to the material. If material is not included in the article's Creative Commons licence and your intended use is not permitted by statutory regulation or exceeds the permitted use, you will need to obtain permission directly from the copyright holder. To view a copy of this licence, visit http://creativecommons.org/licenses/by/4.0/ The Creative Commons Public Domain Dedication waiver (http://creativecommons.org/publicdomain/zero/1.0/) applies to the data made available in this article, unless otherwise stated in a credit line to the data. 


\section{Background}

Healthy eating is an essential issue of health promotion and has gained increasing relevance in tackling chronic noncommunicable diseases worldwide [1]. The current epidemiological nutritional context in developing countries, where malnutrition and micronutrient deficiency coexist, and the emergence of an epidemic of overweight and obesity, underscore the importance of promoting healthy eating as a necessary component of the duties of professionals working in primary health care (PHC) [2-5].

Following the evolution in the organization of health work and in the recognition of the multidimensionality of factors that affect the diet, the promotion of healthy eating is increasingly being recognized as a collective effort, based on teamwork [3, 5]. Dietary Guidelines incorporate recommendations for a healthy diet and bring them closer to the regional realities of different countries, therefore, they are considered important tools to guide the performance of health professionals, especially at PHC services [6]. The new edition of the Brazilian Dietary Guidelines (BDG) brought an important update of the paradigm and recommendations on healthy eating. The BDG is internationally recognized for its innovation in considering emerging issues, such as sustainability, and for adopting a food classification based on the extent and purpose of industrial processing, recently assumed as a marker of global food quality [7, 8].

In Brazil, health has been recognized in the federal constitution as a right of citizens and a duty of the state since 1988. The Brazilian public health care system was established under the premises of universality, comprehensiveness and social participation [9] and the primary care is the entry point to the system. Considering this context, PHC professionals are key components in the dissemination of the Dietary Guidelines recommendations due to their access to and bonds with the population interacting with the various care levels of the health system $[5,6]$.

However, even though the potential impact of recommendations made by health professionals for changes in users' behavior is recognized, little is incorporated into their practice, either due to the insufficient nutrition training offered to these professionals, the difficulty in addressing issues about food, and / or by possible barriers to implement changes in professional practice to guide individuals about food [10-12]. Considering these aspects, interventions that seek to increase knowledge and impact behavioral aspects such as self-efficacy and collective efficacy have been widely used in health education processes [12-14].

Self-efficacy and collective efficacy are constructs of the social cognitive theory, which refer to "an individual person's perception of ability to perform a behavior" and “a group's shared belief in its capability to organize and execute actions required to achieve goals" respectively [15]. Collective efficacy is considered an extension of the self-efficacy construct. In this sense, this study adopts these constructs believing that health professionals properly trained in nutrition improve their knowledge and their perception of self-efficacy and collective efficacy to counsel on health eating, either individually or as a team, improving the quality of care offered to the population.

Therefore, given the importance of these attributes in promoting healthy eating, this study aims to assess the effect of an educational intervention based on the Brazilian Dietary Guidelines on the knowledge, self-efficacy and collective efficacy of professionals working in PHC.

\section{Methods}

Design, setting and participants

To expand the coverage and problem-solving capacity of Brazilian primary health care system, were established Family Health Support Centres (NASFs, for its acronym in Portuguese), composed of multidisciplinary teams that work in an integrated manner with the PHC teams [16]. The NASFs operate according to the logic of interprofessional collaborative practice (ICP), which takes place when professionals from different areas provide services based on comprehensive health, involving patients and their families, caregivers and communities to provide the highest quality of care at all levels of the health care network [17].

In this context, the present study was a controlled community trial with a pre- and posttest design with professionals working in the NASFs of a medium-sized Brazilian municipality with approximately 400,000 inhabitants. All professionals registered and working in multidisciplinary NASF teams in the municipality were invited to voluntarily participate in the study. The municipality had four multidisciplinary NASF teams and each team was the reference team for approximately 8 to 10 basic health units, with the primary care system of the municipality covering approximately $53.7 \%$ of the population.

\section{Intervention: dietary guidelines for the Brazilian population workshop}

The intervention protocol was developed intentionally to improve knowledge regarding to the Brazilian Dietary Guidelines (hereinafter referred to as the Guidelines), and to promote self-efficacy and collective-efficacy of health professionals teams to disseminate and translate the Guideline's recommendations. The protocol was guided by three main theoretical references: the Guidelines, which are a technical evidence-based reference for the country in the field of food and nutrition; adultlearning theory, which is based on the critically reflective 
methodology developed by educator Paulo Freire [18], which in turn is based on the active participation of subjects, joint construction of knowledge and different teaching strategies; and the assumptions of ICP [17], linked to the PHC teamworks' procedures, ICP occurs when different health professionals provide services based on a collaborative approach to care individuals and communities.

The educational intervention consisted of a workshop of $16 \mathrm{~h}$ of training divided into four four-hour modules. The activities were designed to allow the participants to rescue previous knowledge, analyse their work context reality and, from this, collectively construct concepts, reflect on their practice in a multiprofessional team and propose strategies for intervention at work using the Dietary Guidelines as the main technical reference for the activities. For that, the activities were developed and organized in three axes: (a) organizational strategies, referent to activities that present the workshop and the team, welcome participants and establish ground rules; closure and evaluation; (b) dietary guideline comprehension, addresses the content of each chapter of the document, emphasizing its recommendations; and (c) dietary guideline implementation, intended to contextualize the recommendations in professional practice and assist in the application of the guidelines as a tool for the promotion of healthy eating. The educational intervention methodological framework is described in Fig. 1.

The workshop was previously tested on five NASF teams from a municipality of similar size and context. With the purpose of testing its reproducibility in other teams in the country, the protocol was also validated by a panel of experts through content validation regarding its relevance, its clarity and the theoretical framework used for its development. The protocol and its validation are described in detail in a previous publication [19].

The health professionals were allocated nonrandomized into an intervention group (IG) and a control group (CG) according to the distribution of the teams in the municipality's territory to minimize the cross contamination of information about the intervention between the groups.

The IG attended the workshop, which was led by facilitators previously trained by the team of responsible researchers and an observer who tracked the execution and adequacy of the intervention protocol. The workshop took place over 2 days during the working hours of the health teams. Participants in the CG did not change their routines during the intervention period. At the end of the study, the CG received the same training given to the IG. The flowchart for the study is shown in Fig. 2.

\section{Outcomes}

The effect of the intervention was evaluated through the analysis of three outcomes: a) the health professionals' knowledge about the content of the Guidelines, b) self-efficacy and c) collective efficacy, understood to be the confidence or belief in the ability of the individual or group, respectively, to develop and execute the actions necessary to achieve certain results or desired change, understood in this study as the confidence or belief in the ability to promote nutrition counseling based on the Guidelines.

Sociodemographic data were collected using selfadministered questionnaires before the educational intervention. The outcomes of interest were measured using self-administered scales previously validated [20]. The knowledge scale consisted of 16 statements about the

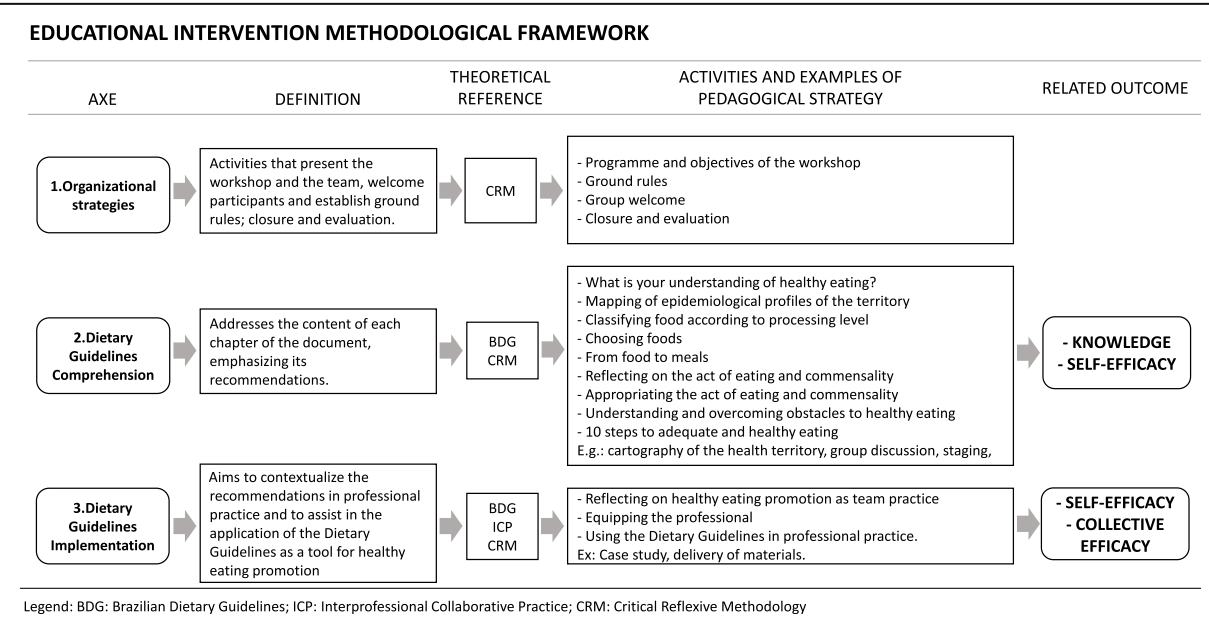

Fig. 1 Educational intervention methodological framework for implementing the Dietary Guidelines for the Brazilian Population. Jundiaí, Brazil, 2019. Legend: BDG: Brazilian Dietary Guidelines; ICP: Interprofessional Collaborative Practice; CRM: Critical Reflexive Methodology 


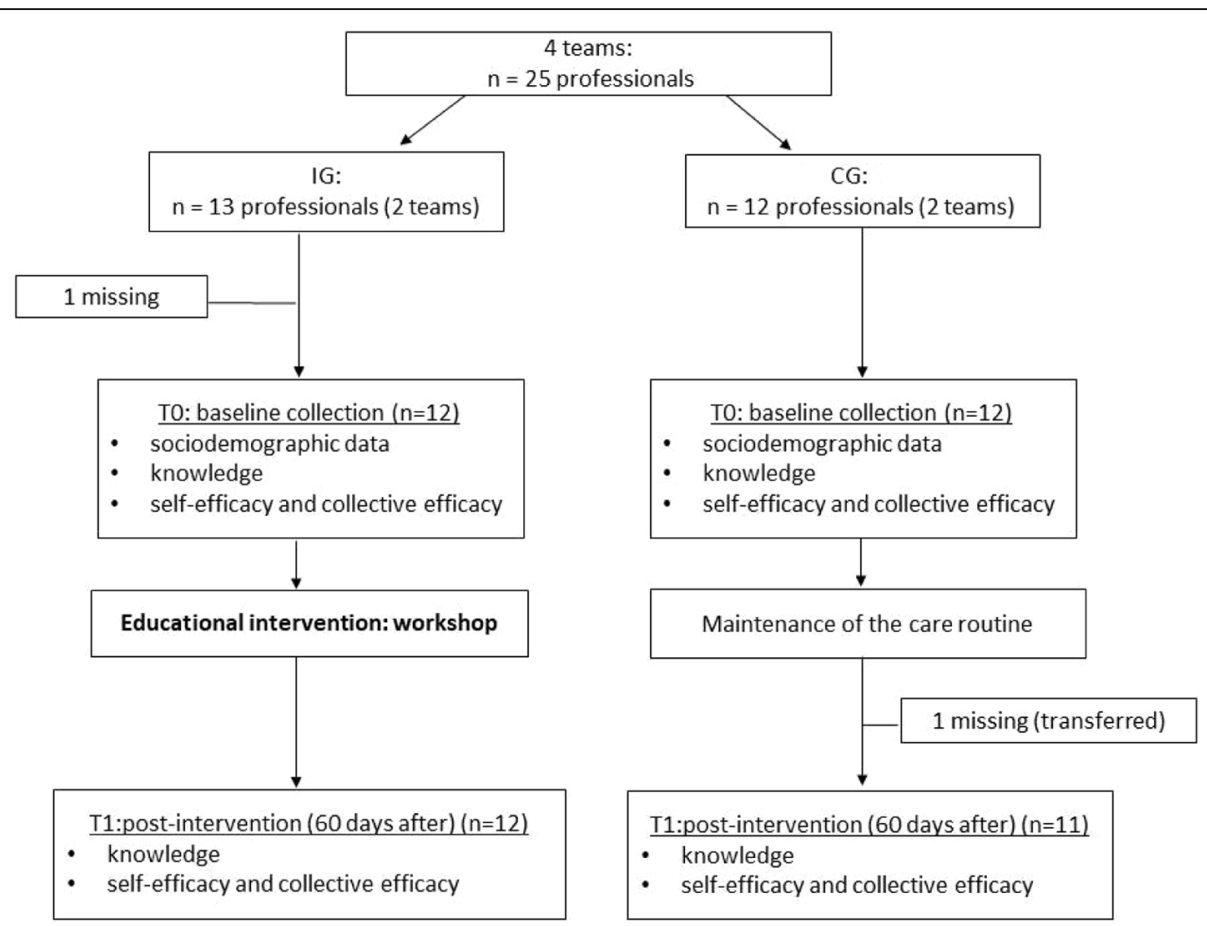

Fig. 2 Flowchart of the educational intervention in multi-professional health teams for implementing the Dietary Guidelines for the Brazilian Population. Jundiaí, Brazil, 2019

recommendations contained in the five chapters of the Guidelines, with three answer options ("true", "false" and "I don't know"). Each correct question gave participants a point, generating a knowledge score that ranged from 0 to 16 points. The scales that evaluated self-efficacy and collective efficacy were composed of 12 questions each with four-point responses on the Likert scale that assessed selfefficacy, ranging from $0=$ not confident to $3=$ very confident, and collective efficacy, ranging from $0=$ false to $3=$ very true. Each scale generated a final score ranging from 0 to 36 points. The score of knowledge, self-efficacy and collective efficacy was calculated using the average score of each group. The Table 1 shows samples of knowledge, self-efficacy and collective efficacy questions. The outcomes were evaluated on-site in both groups (IG and CG) before the intervention and 60 days after its completion by trained researchers who were not involved with the educational intervention. Understanding that the outcomes investigated in this study require time for professionals to be able to make connections with what was learned in the intervention and the work practice considering the dynamics of health services, it was assumed that the post-test would be better performed 60 days after the application of the intervention.

\section{Data analysis}

All analyses were performed using Stata SE 14.1 (Stata Corp., College Station. Texas, USA). All questionnaires were double entered to ensure accuracy. All the normal distribution of the data was assessed by the ShapiroWilk test and a histogram. Differences in the sociodemographic characteristics at baseline for the IG and CG were analysed. For analyses between groups, the Fisher's exact test was used to compare categorical data; MannWhitney test was used to analyse continuous variables with no equal distributions; and t-test was used for continuous data with equal distribution. A paired t-test was used for intragroup comparison at T0 versus T1. Statistical significance was accepted at the level of $p<0.05$.

This study was approved by the research ethics committee of the University of São Paulo School of Public Health (Faculdade de Saúde Pública da Universidade de São Paulo) and by the Municipal Health Department, and the participants voluntarily signed an informed consent form.

\section{Results}

The characteristics of the study groups are presented in Table 2. The IG and CG did not differ at baseline with regard to the sociodemographic characteristics, professional categories that composed the teams, length of professional training, time working in the team or with regard to the knowledge, self-efficacy and collective efficacy scores. Eight professionals in each group reported already having knowledge of the guidelines. 
Table 1 Examples of knowledge, self-efficacy and collective efficacy questions used in each scale

\begin{tabular}{|c|c|}
\hline Question & Score \\
\hline \multicolumn{2}{|l|}{ Knowledge } \\
\hline $\begin{array}{l}\text { Potatoes, rice, beans, chestnuts and walnuts are } \\
\text { foods that should be avoided to prevent weight gain. }\end{array}$ & $\begin{array}{l}\text { 1-True } \\
\text { 2- False } \\
\text { 3- Do not } \\
\text { know }\end{array}$ \\
\hline \multicolumn{2}{|l|}{ Self-efficacy } \\
\hline $\begin{array}{l}\text { I can advise health service users to combine foods in } \\
\text { the form of healthy meals. }\end{array}$ & $\begin{array}{l}\text { 0-not } \\
\text { confident } \\
\text { 1-a little } \\
\text { confident } \\
\text { 2-confident } \\
\text { 3-very } \\
\text { confident }\end{array}$ \\
\hline \multicolumn{2}{|l|}{ Collective efficacy } \\
\hline $\begin{array}{l}\text { My team is able to advise health care users to } \\
\text { combine foods in the form of healthy meals. }\end{array}$ & $\begin{array}{l}\mathbf{0} \text { - false } \\
\mathbf{1} \text {-sometimes } \\
\text { true } \\
\text { 2-true } \\
\text { 3-very true }\end{array}$ \\
\hline
\end{tabular}

In the analysis of the variation over time (T1-T0), the outcomes with the greatest variations in the IG were self-efficacy, with a mean score difference of 6.75 points $(p<0.001)$, followed by knowledge, with a mean score difference of 2.0 points $(p=0.007)$, which means an increase of 59 and $52.8 \%$ on knowledge and perception of $\mathrm{SE}$, respectively, in those professionals who participated in the educational intervention. There was no significative variation on $\mathrm{CE}$ scores over time. For the $\mathrm{CG}$, there were no significant variations in the mean scores of the outcomes before and after the intervention. (Table 3).

\section{Discussion}

The present study assessed an educational intervention undertaken with professionals of Family Health Support Centres seeking to improve the knowledge, self-efficacy and collective efficacy to promote health eating based on Brazilian Dietary Guidelines. The results were positive in terms of improving the professionals' knowledge and self-efficacy regarding the current recommendations for health eating in the IG compared over time.

Table 2 Sociodemographic characterization and distribution of outcome scores of the groups at baseline $(N=24)$. Jundiaí, Brazil, 2019

\begin{tabular}{|c|c|c|c|}
\hline & \multicolumn{2}{|l|}{ Group } & \multirow[b]{2}{*}{ Significance test } \\
\hline & $\begin{array}{l}\text { Control } \\
\text { n (\%) }\end{array}$ & $\begin{array}{l}\text { Intervention } \\
\text { n (\%) }\end{array}$ & \\
\hline \multicolumn{4}{|l|}{ Sex } \\
\hline M & $4(33.3)$ & $3(25)$ & \\
\hline $\mathrm{F}$ & $8(66.7)$ & $9(75)$ & $0.203^{*}$ \\
\hline \multicolumn{4}{|l|}{ Occupation } \\
\hline Social worker & $2(16.7)$ & $2(16.7)$ & \\
\hline Physical educator & $2(16.7)$ & $3(25)$ & \\
\hline Physical therapist & $2(16.7)$ & $2(16.7)$ & \\
\hline Nutritionist & $2(16.7)$ & $1(8.3)$ & \\
\hline Psychologist & $2(16.7)$ & $2(16.7)$ & \\
\hline Occupational therapist & $2(16.7)$ & $2(16.7)$ & $0.533^{*}$ \\
\hline \multicolumn{4}{|c|}{ Did you have prior knowledge of the Dietary Guidelines? } \\
\hline Yes & $8(66.7)$ & $8(66.7)$ & \\
\hline \multirow[t]{2}{*}{ No } & $4(33.3)$ & $4(33.3)$ & $1.000^{*}$ \\
\hline & Mean (SD) & Mean (SD) & \\
\hline Age & $42.08(11.18)$ & $37.36(8.3)$ & $0.3548^{* *}$ \\
\hline Length of professional training (years) & $15.92(12.27)$ & $10(7.27)$ & $0.3875^{* *}$ \\
\hline \multirow[t]{2}{*}{ Time working at the FHSC (months) } & 24. $9(11.82)$ & $21.08(11.85)$ & $0.416^{* *}$ \\
\hline & Mean $(\mathrm{Cl})$ & Mean $(\mathrm{Cl})$ & \\
\hline Knowledge score & 12.25 (10.67 to 13.83$)$ & 10.83 (9.43 to 12.24$)$ & $0.1546^{\mathrm{a}}$ \\
\hline Self-efficacy score & 18.25 (1.69 to 5.61$)$ & 16.08 (24.33 to 31.83$)$ & $0.3748^{\mathrm{a}}$ \\
\hline Collective efficacy score & 23.58 (19.28 to 27.89$)$ & 25.42 (21.73 to 29.11$)$ & $0.4841^{\mathrm{a}}$ \\
\hline
\end{tabular}

*Fisher's exact test: $\mathrm{p}<0.05$

**Mann-Whitney test $p<0.05$

a Student's t-test 
Table 3 Effect of the intervention on knowledge, self-efficacy and collective efficacy $(N=24)$. Jundiaí, Brazil, 2019

\begin{tabular}{|c|c|c|c|c|c|c|c|c|}
\hline & \multicolumn{4}{|c|}{ Intervention group $(\boldsymbol{n}=12)$ mean $(95 \% \mathrm{Cl})$} & \multicolumn{4}{|c|}{ Control group $(\boldsymbol{n}=11)$ mean $(95 \% \mathrm{Cl})$} \\
\hline & $\mathrm{T}_{0}$ & $\mathrm{~T}_{1}$ & $\Delta$ & $\mathrm{p}$ & $\overline{T_{0}}$ & $\mathrm{~T}_{1}$ & $\Delta$ & $\mathrm{p}$ \\
\hline Knowledge & $\begin{array}{l}10.83 \\
\text { (9.43 to } 12.24 \text { ) }\end{array}$ & $\begin{array}{l}12.83 \\
\text { (10.72 to } 14.95)\end{array}$ & $\begin{array}{l}2.0 \\
(0.49 \text { to } 3.51)\end{array}$ & 0.007 & $\begin{array}{l}12.25 \\
\text { (10.67 to } 13.83)\end{array}$ & $\begin{array}{l}13.64 \\
\text { (11.88 to } 15.39)\end{array}$ & $\begin{array}{l}0.82 \\
(-0.34 \text { to } 1.97)\end{array}$ & 0.073 \\
\hline Self-efficacy & $\begin{array}{l}16.08 \\
\text { (12.33 to } 19.83)\end{array}$ & $\begin{array}{l}22.83 \\
\text { (19.63 to } 26.04 \text { ) }\end{array}$ & $\begin{array}{l}6.75 \\
(4.05 \text { to } 9.45)\end{array}$ & $<0.001$ & $\begin{array}{l}18.91 \\
\text { (15.14 to } 22.68)\end{array}$ & $\begin{array}{l}22.09 \\
\text { (16.29 to } 27.89 \text { ) }\end{array}$ & $\begin{array}{l}3.18 \\
(-0.74 \text { to } 7.11)\end{array}$ & 0.051 \\
\hline $\begin{array}{l}\text { Collective } \\
\text { efficacy }\end{array}$ & $\begin{array}{l}25.42 \\
(21.73 \text { to } 29.11)\end{array}$ & $\begin{array}{l}25.25 \\
\text { (21.64 to } 28.86)\end{array}$ & $\begin{array}{l}-0.17 \\
(-2.83 \text { to } 2.49)\end{array}$ & 0.553 & $\begin{array}{l}23.09 \\
\text { (18.47 to } 27.71)\end{array}$ & $\begin{array}{l}20.82 \\
\text { (15.35 to } 26.29)\end{array}$ & $\begin{array}{l}-2.27 \\
(-6.59 \text { to } 2.04)\end{array}$ & 0.866 \\
\hline
\end{tabular}

The change in the level of knowledge is commonly the most prevalent outcome of interest in studies that carry out some type of training in nutrition with health professionals, followed by changes in attitudes, selfreported practices, self-efficacy, confidence and feedback [21, 22].

In most cases, knowledge is positively impacted by interventions; however, some methodological differences can be found when compared to this study. The absence of comparison with CG is the main point of divergence, followed by aspect referred to the knowledge investigation questionnaires, which for the most part have not been validated for use in the study, raising questions about the validity of the answers found, and confirm the reliability of the results presented by this study [21, 22]. In addition, another relevant factor is the time after the intervention within which knowledge is measured. Knowledge is usually measured within a short period of time to minimize participants' memory bias [21]. Knowledge is usually lost over time if not put into practice or resumed and must be relearned throughout a continuous education process [23]. This study, however, demonstrated that the participants obtained a relevant gain of knowledge even after 2 months of the educational intervention. This may mean that the participants, in addition to increasing knowledge, were able to retain the knowledge acquired in the medium term - 60 days after the intervention. A short- and long-term evaluation would allow confirmation and assessment of the permanence of the effect over time.

The perception of self-efficacy increased significantly within the time variation in this population. Few studies have found positive results for self-efficacy, either alone or in combination with knowledge [21]. It is a consensus in the literature that professionals who, in addition to being better trained, feel confident in performing certain actions are more likely to rethink their practices and change their attitudes [24, 25].

According to the SCT, self-efficacy is mutually influenced by individuals' behavioral, environmental and personal factors [15], characteristics which do not depend exclusively on the educational intervention delivered. In this study, the format of the educational intervention - which made use of active teaching methods that imparted meaningful learning to the participants and which sought to develop skills and not only knowledge -, may have convincing participants about the relevance of the theme, since individuals seemed to feel more confident to advise about healthy eating based on the Dietary Guidelines. According to Mogre et al., teaching methods play a decisive role in the positive impact of nutritional interventions [21].

Another important point to be discussed is that part of the effect of the intervention on knowledge and SE, can be attributed to the educational tool itself - the Brazilian Dietary Guidelines. Its expanded approach on the dimensions that involve food, meals and ways of eating, considering biological, cultural, economic and environmental aspects, may have come closer to the competences perceived by these health professionals. NASFs who received the educational intervention seemed to appropriate of the content delivered and identified that advice on healthy eating is part of its duties, considering the logic of interprofessional collaborative practice.

No effect of the educational intervention was observed on the collective efficacy of the health professionals comparing post and pre-intervention time. In fact, both groups already had high $\mathrm{CE}$ at the beginning of the study, which made it difficult to demonstrate an effect on this outcome. This result may be related to factors external to the intervention that are associated with team-work dynamics. The fact that the professionals trusted in the capabilities of their teams to advise on healthy eating, perhaps means that they performed satisfactory teamwork. Therefore, the efficient interprofessional collaborative practice performed by these teams, highly supported by the local government in the context of this study, may have contributed to their high perception of CE [26, 27]. This result reinforces the importance of the workforce qualification processes being supported by a policy of continuing health education, which strengthens the premises of interprofessional collaborative practice at PHC $[27,28]$.

Previous studies have noted that achieving effective ICP impacts is complex and requires interventions that focus on improving communication, stimulating trust 
among team members and investing in intersectorally coordinated actions such that the health care processes become more durable [17, 29, 30]. Work settings and organizational barriers are fundamental to understanding the feasibility and effectiveness of interventions that are applied under real working conditions $[28,30]$. In this sense, to promote healthy eating guidelines, further research should be conducted to stimulate the development of competencies, self-efficacy and specific skills for collaborative teamwork, considering that these multidisciplinary teams have been successful models to health systems organization [31].

Although the participants were not randomly allocated to the intervention or control groups in the present study, the differences between the groups at baseline were not significant, and therefore, should not have interfered on the results presented in this study.

One additional factor deserving of consideration is the possible induction effect resulting from the completion of questionnaires by the participants prior to the intervention. This action might have favourably influenced the results of the second assessment by raising the professionals' awareness regarding to the investigated topics, thereby leading them to seek information, discuss the topics more frequently in their routines, or both, typical of studies applied under real service conditions. However, because significative increased on outcomes investigated based on the second questionnaire was not observed in the control group, it may be inferred that the results were due to the educational intervention.

The validity of the results is also supported by the procedure used to assess the between-group differences regarding the knowledge and perception of self-efficacy of health professionals. Traditionally, assessment of this outcomes is based on professionals self-reports [21, 32]. The scales used to assess the outcomes in this study were previously validated by a rigorous five-step process: content validation with panel of experts, face validation with potential users, online reevaluation by health professionals and experts, online application with PHC professionals working all over Brazil's macro-regions and confirmatory factor analysis to investigate construct validity [33]. The use of these scales to assess the knowledge of health professionals about the dietary guidelines, as well as their self-efficacy and collective efficacy preceptions to guide healthy eating, guarantees more reliability to the results found.

The small sample size in this study is a limiting factor for more robust analyzes typical of clinical trials, which hinders the reproducibility and extrapolation of the results. However, the nature of the intervention performed in a real service context, and the positive effect observed on the IG, are strengths of this study. Most studies on educational intervention in nutrition focus only on doctors, nurses or graduate students, and aim to implement clinical protocols or recommendations focused on a determined aspect of nutrition, such as professional training on breastfeeding [21, 34-37]. Few studies carry out training of health teams with such diversity of professional categories as presented in this study. It is therefore believed that the population of this study is a representative sample of professional diversity in the Brazilian PHC system. In light of methodologies commonly used in nutrition intervention studies, we also highlight that the methodological rigor sought in all steps of this study is scarce to find in literature.

The applicability of the intervention protocol that was developed and tested in the present study is also highlighted. It was published by the Brazilian Ministry of Health as an instructional manual entitled "Implementing the Dietary Guidelines for the Brazilian Population in Teams Working in Primary Care (Implementando o Guia Alimentar para a População Brasileira em equipes que atuam na Atenção Básica) [38]. Brazil has a recognized history of implementing governmental strategies to promote healthy eating practices [39-41], and this represents an established initiative. The publication of this material opens up possibilities for the intervention to become a national strategy for training professionals, contributing to the implementation of the Dietary Guidelines in health teams throughout the country. Its country-wide dissemination will allow further evaluation to be performed using larger and more representative samples to compare the results presented in this study.

Since the professionals who participated in the training about Brazilian Dietary Guidelines increased their knowledge and felt more confident to advise on food, the findings of this study point to the need for investments in capacity building for health professionals to deal with nutrition issues, in view of the emergence of the current epidemiological scenario. There is a need for nutrition to be recognized as an interdisciplinary field and to be considered from professional training, including it in higher education curricula. In addition to academic training, it is important to consider that continuing professional education processes must be carried out, including training in nutrition, in order to improve multiprofessional teams' practice.

We recognize the need for future studies to determine whether the educational intervention influenced the nutritional counseling behavior of professionals in the real context of in-service practice.

\section{Conclusions}

The educational intervention demonstrated to be effective in increasing knowledge about the Dietary Guidelines and improving the perception of self-efficacy to advise on healthy eating in health professionals. The results 
presented in this study reinforce the importance of training PHC health professionals on nutrition. In addition, it legitimizes the importance of investing in continuing education processes in multiprofessional health teams for the implementation of official dietary guidelines.

\section{Abbreviations}

BDG: Brazilian dietary guidelines; CG: Control group; CE: Collective efficacy; ICP: Interprofessional collaborative practice; IG: Interventional group; NASF: Family Health Support Centres (Núcleo de Apoio a Saúde da Familia NASF for its acronym in Portuguese); PHC: Primary Health Care; SE: Self efficacy

\section{Acknowledgements}

The authors would like to acknowledge all the health professionals who voluntarily participated in this study.

\section{Authors' contributions}

CRT contributed to the data collection, data analysis, interpretation and writing of first and subsequent drafts of the paper. PCJ contributed to the design, interpretation and review of the first and subsequent drafts of the paper. Both authors read and approved the complete version of this manuscript.

\section{Funding}

Cost relative to data collection and publication fees were supported by the National Council for Scientific and Technological Development (CNPq) [grant number 409733/2016-4]. International Development Research Centre (IDRC) [grant number 108166] financed the printing of the educational materials used in the intervention study. The first author received a doctoral scholarship provided by Coordination for the Improvement of Higher Education Personnel (CAPES). The sponsor agencies did not get involved with design, analyses, interpretation and writing steps of the manuscript.

\section{Availability of data and materials}

The datasets used and/or analysed during the current study are available from the corresponding author on reasonable request.

\section{Ethics approval and consent to participate}

This study was approved by the research ethics committee of the University of São Paulo School of Public Health (Faculdade de Saúde Pública da Universidade de São Paulo) and by the Municipal Health Department, and the participants voluntarily signed an informed consent form.

\section{Consent for publication}

Not Applicable.

\section{Competing interests}

The authors declare that they have no competing interests.

\section{Author details}

${ }^{1}$ Nutrition in Public Health Postgraduate Program, School of Public Health, University of São Paulo, Av. Dr. Arnaldo 715, São Paulo, SP 01246-904, Brazil. ${ }^{2}$ Department of Nutrition, School of Public Health, University of São Paulo, Av. Dr. Arnaldo 715, São Paulo, SP 01246-904, Brazil.

Received: 16 April 2020 Accepted: 11 August 2020

Published online: 21 October 2020

\section{References}

1. Afshin A, Sur PJ, Fay KA, Cornaby L, Ferrara G, et al. Health effects of dietary risks in 195 countries, 1990-2017: a systematic analysis for the global burden of disease study 2017. Lancet. 2019;393(10184):1958-72.

2. Delisle, H., Shrimpton, R., Blaney, S., Du Plessis, L., Atwood, S., Sanders, D., Margetts, B. Capacity-building for a strong public health nutrition workforce in low-resource countries. Bull World Health Organ 2017; 95(5), 385-388.

3. Shrimpton R, du Plessis LM, Delisle H, Blaney S, Atwood SJ, et al. Public health nutrition capacity: assuring the quality of workforce preparation for scaling up nutrition programmes. Public Health Nutr. 2016;19(11):2090-100 Epub 2016 Feb 9.
4. Hodge A. Opportunities for nutrition in primary care. Public Health Nutr 2020;23(1):1-2.

5. Kris-Etherton PM, Akabas SR, Douglas P, Kohlmeier M, laur C, et al. Nutrition competencies in health professionals; education and training: a new paradigm. Adv Nutr. 2015;6(1):83-7.

6. World Health Organization, Food and Agriculture Organization of the United Nations. Preparation and use of food based dietary guidelines. Nicosia: Joint FAO/WHO Consultation; 1996.

7. Brasil. Ministério da Saúde. Guia alimentar para a população brasileira / Ministério da Saúde, Secretaria de Atenção à Saúde, Departamento de Atenção Básica. 2nd ed. Brasília: Ministério da Saúde; 2014. [Brazil. Ministry of Health of Brazil. Secretariat of Health Care. Primary Health Care Department. Dietary Guidelines for the Brazilian population / Ministry of Health of Brazil, Secretariat of Health Care, Primary Health Care Department. Brasilia: Ministry of Health of Brazil, 2015.].

8. Monteiro CA, Cannon G, Lawrence M, Costa Louzada ML, Pereira Machado P. Ultra-processed foods, diet quality, and health using the NOVA classification system. FAO: Rome; 2019

9. Paim J, Travassos C, Almeida C, Bahia L, Macinko J. The Brazilian health system: history, advances, and challenges. Lancet. 2011;377(9779):1778-97.

10. Kris-Etherton PM, Akabas SR, Bales CW, Bistrian B, Braun L, et al. The need to advance nutrition education in the training of health care professionals and recommended research to evaluate implementation and effectiveness. Am J Clin Nutr. 2014;99(5 Suppl):1153S-66S.

11. Food and Agriculture Organization of the United Nations. The need for professional training in nutrition education and communication. Final report. 2011. Available at http://www.fao.org/ag/humannutrition/29494-0e1 8d2bbf4a9299faa8945f84f3e08a07.pdf.

12. Lucas CJ, McMahon AT, Charlton KE. Developing professional education for primary healthcare providers about nutrition. Aust J Prim Health. 2019;25(6): 534-8.

13. Bumann M, Younkin S. Applying self efficacy theory to increase interpersonal effectiveness in teamwork. J Invitational Theory Pract. 2012; Annual, vol 18.

14. Bandura A. Health promotion from the perspective of social cognitive theory. Psychol Health. 1998;13:623-49.

15. Bandura A. Teoria Social Cognitiva: Conceitos Básicos. Porto Alegre: Artmed; 2008. [Bandura A. Cognitive Social Theory: Basic Concepts. Porto Alegre, Artmed, 2008]

16. Castro M, Massuda A, Almeida G, Menezes-Filho NA, et al. Brazil's unified health system: the first 30 years and prospects for the future. Lancet. 2019; 394:345-56

17. World Health Organization. Framework for action on interprofessional education and collaborative practice. Geneva: Department of Human Resources for Health; 2010.

18. Freire P. Pedagogy of the oppressed. New York: Continuum; 2005

19. Jaime PC, Tramontt CR, Gabe KT, Reis LC, et al. Content validity of an educational workshop based on the dietary guidelines for the Brazilian population. Rev Nutr. 2018:31(6):593-602.

20. Reis LC, Jaime PC. Conhecimento e percepção de autoeficácia e eficácia coletiva de profissionais de saúde para a implementação do guia alimentar na atenção básica. (Knowledge and perceived selfefficacy and collective efficacy of health professionals to implement the Brazilian dietary guidelines in primary health care). Demetra Food Nutr Health / Alimentação Nutr Saúde. 2019:14:1-20 11p.

21. Mogre V, Scherpbier AJ, Stevens F, Aryee P, et al. Realist synthesis of educational interventions to improve nutrition care competencies and delivery by doctors and other healthcare professionals. BMJ Open. 2016;6(10):e010084.

22. Sunguya BF, Poudel KC, Mlunde LB, Urassa DP, Yasuoka J, Jimba M. Nutrition training improves health workers' nutrition knowledge and competence to manage child undernutrition: a systematic review. Front Public Health. 2013:1:37.

23. Dhaliwal JS, Benbasat I. A framework for the comparative evaluation of knowledge acquisition tools and techniques. Knowl Acquis. 1990;2(2):145-66.

24. Fahlman M, McCaughtry N, Martin J, Shen B. Efficacy, intent to teach, and implementation of nutrition education increases after training for health educators. Am J Health Educ. 2011;42(3):181-90.

25. Stark CM, Graham-Kiefer ML, Devine CM, Dollahite JS, Olson CM. Online course increases nutrition professionals' knowledge, skills, and self-efficacy in using an ecological approach to prevent childhood obesity. J Nutr Educ Behav. 2011:43(5):316-22. 31 
26. Silva JAM, Peduzzi M, Orchard C, Leonello VM. Educação interprofissional e prática colaborativa na Atenção Primária à Saúde. [Interprofessional education and collaborative practice in primary health care]. Rev Esc Enferm USP. 2015;49(spe2):16-24.

27. Gittell JH, Godfrey M, Thistlethwaite J. Interprofessional collaborative practice and relational coordination: improving healthcare through relationships. J Interprof Care. 2013;27(3):210-3.

28. Schmitt M, Blue A, Aschenbrener CA, Viggiano TR. Core competencies for interprofessional collaborative practice: reforming health care by transforming health professionals' education. Acad Med. 2011;86(11):1351.

29. Foronda C, MacWilliams B, McArthur E. Interprofessional communication in healthcare: an integrative review. Nurse Educ Pract. 2016;19:36-40.

30. Shah HD, Adler J, Ottoson J, Webb K, Gosliner W, et al. Experiences in planning, implementing, and evaluating complex public health nutrition interventions. J Nutr Educ Behav. 2019:51(5):528-38.

31. Morgan S, Pullon S, McKinlay E. Observation of interprofessional collaborative practice in primary care teams: an integrative literature review. Int J Nurs Stud. 2015;52(7):1217-30.

32. Bumann M \&amp; Younkin S. Applying self efficacy theory to increase interpersonal effectiveness in teamwork. J Invitational Theory Pract. 2012. Annual, vol 18.

33. Reis LC. Tecnologias de apoio para implementação do Guia Alimentar para a População Brasileira na Atenção Básica. [Technologies to support the implementation of the dietary guidelines for the Brazilian population in primary health care]. [Thesis]. São Paulo: School of Public Health. University of São Paulo; 2019.

34. Levy J1, Harris J, Darby P, Sacks R, Dumanovsky T, Silver L. The primary care nutrition training program: an approach to communication on behavior change. Health Promot Pract. 2011;12(5):761-8.

35. Cadman L1, Findlay A. Assessing practice nurses' change in nutrition knowledge following training from a primary care dietitian. J R Soc Promot Heal. 1998;118(4):206-9.

36. Wilcox S, Parra-Medina D, Felton GM, Poston MB, McClain A. Adoption and implementation of physical activity and dietary counseling by community health center providers and nurses. J Phys Act Health. 2010;7(5):602-12.

37. Santos IS, Victora CG, Martines J, Gonçalves H, et al. Avaliação da eficácia do aconselhamento nutricional dentro da estratégia do AIDPI (OMS/UNICEF). Rev Bras Epidemiol. 2002;5(1):15-29.

38. Brasil. Ministério da Saúde. Manual instrutivo : implementando o guia alimentar para a população brasileira em equipes que atuam na Atenção Primária à Saúde [recurso eletrônico] / Ministério da Saúde. Ministério da Saúde: Universidade de São Paulo. - Brasília; 2019.

39. Jaime PC, Silva DACF, Lima DAMC, Bortolini GA. Ações de alimentação e nutrição na atenção básica: a experiência de organização no Governo Brasileiro. [Food and nutrition actions in primary healthcare: the experience of the Brazilian government]. Rev Nutr. 2011;24(6):809-24.

40. World Cancer Research Fund International. NOURISHING framework. Nutrition counselling in primary care e Training for health professionals. https://www.wcrf.org/sites/default/files/9_Nutrition\%20Advice\%20and\%2 OCounselling_FallMay2019.pdf. Accessed 15 June 2019.

41. World Health Organization. Global database on the Implementation of Nutrition Action (GINA). https://extranet.who.int/nutrition/gina/. Accessed 6 Aug 2019.

\section{Publisher's Note}

Springer Nature remains neutral with regard to jurisdictional claims in published maps and institutional affiliations.

Ready to submit your research? Choose BMC and benefit from:
- fast, convenient online submission
- thorough peer review by experienced researchers in your field
- rapid publication on acceptance
- support for research data, including large and complex data types
- gold Open Access which fosters wider collaboration and increased citations
- maximum visibility for your research: over 100M website views per year
At BMC, research is always in progress.
Learn more biomedcentral.com/submissions

